OPEN ACCESS

Edited by:

Zhiyong Gao,

Central South University, China

Reviewed by:

Wengang Liu,

Northeastern University, China

Snežana Papović,

University of Novi Sad, Serbia

${ }^{*}$ Correspondence:

Christian Weber

chris.weber@mvtat.tu-freiberg.de

Specialty section:

This article was submitted to Colloidal Materials and Interfaces,

a section of the journal

Frontiers in Materials

Received: 13 September 2019 Accepted: 05 February 2020

Published: 21 February 2020

Citation:

Weber $C$ and Peuker UA (2020) On

the Role of Hydrolyzable Metal Cations in the Adsorption of Anionic

Surfactants on Negatively Charged

Surfaces. Front. Mater. 7:40.

doi: 10.3389/fmats.2020.00040

\section{On the Role of Hydrolyzable Metal Cations in the Adsorption of Anionic Surfactants on Negatively Charged Surfaces}

\author{
Christian Weber* and Urs A. Peuker \\ Mechanical Engineering and Mineral Processing, TU Bergakademie Freiberg, Freiberg, Germany
}

The role of hydrolyzable metal ions in the adsorption of anionic surfactants on a negatively charge surface is studied by electrophoresis and phase transfer experiments. The notion that the presence of such hydrolyzable species (activators) can promote flotation is not new, but a detailed mechanistic explanation is lacking. We relate the role of activators to the phenomenon of overcharging, which has been studied rather extensively within colloid and interface science. The experiments conducted in this article show that overcharging is a necessary condition for the adsorption of an anionic surfactant on a negatively charged surface and that the hydrophobization of the studied particles is most effective when overcharging is most pronounced.

Keywords: SDS, phase transfer, two liquid flotation, overcharging, zeta potential, aluminum chloride, hydrolysis, activators

\section{INTRODUCTION}

In the flotation of mineral particles, one often relies on the adsorption of collectors for an effective hydrophobization of the target particles. If the ore to be floated has a very diverse mineralogical composition, there is quite a number of collectors that may selectively adsorb on the target particles. If, however, one is concerned with mineral assemblies that are majorly composed of oxides and silicates, the issue of finding a sufficiently selective collector becomes considerably more difficult. In principle one could try ionic surfactants and rely on electrostatics to achieve selectivity. For an anionic surfactant this would require that the valuable particles are positively charged and all other particles be negatively charged for the anionic surfactant to be electrostatically repelled. Here one relies on a sufficiently large difference between the points of zero charge of the minerals. However, as many oxides and silicates are negatively charged in practical $\mathrm{pH}$ ranges this is not a universal option for silicate-oxide systems. Similar reasoning applies to the selective separation of fine particles across liquid-liquid interfaces, a process the present authors are concerned with Machunsky et al. (2009), and Leistner et al. (2014, 2019).

An appealing alternative to the hydrophobization routes just described is the use of certain inorganic electrolytes to promote the adsorption of an ionic surfactant. Within the flotation literature these inorganic electrolytes are known as activators (Schubert, 1996; Furstenau and Pradip, 2005). Common to all activators is the fact that they show a more or less pronounced, $\mathrm{pH}$-dependent speciation in aqueous solution. By speciation it is understood that hydrolyzed metal cations exist in certain $\mathrm{pH}$ ranges and these are precisely the $\mathrm{pH}$ ranges where best flotation results are obtained with negatively charged particles and anionic collectors (Fuerstenau et al., 1965). The mechanistic idea behind these activators is that they act as a linker between the anionic surfactant 
and the similarly charged surface. Schubert (1996) summarizes that the probable mechanism is the adsorption of the activator in the Stern layer and Furstenau and Pradip (2005) state that the hydrolyzed species show such a high surface activity that they adsorb on any sort of adsorbent and thus provide said link.

The behavior of such hydrolyzed metal electrolytes has attracted interest in colloid and interface science as well (for reviews see Lyklema, 2006, 2013), where it was noticed that the colloid stability is affected quite drastically by such electrolytes. Furthermore, the phenomenon of overcharging-a more or less sudden sign reversal of the $\zeta$-potential as a function of electrolyte concentration-was studied quite intensively.

In this article we will bring the information collected on the overcharging phenomenon in context with the activating electrolytes in flotation. This necessarily requires the description of electric double layers with inorganic electrolytes. The following sections are intended to briefly review the structure of electric double layers and to define the role of charge determining-, indifferent- and specifically adsorbed electrolytes. Furthermore, some information on overcharging and the necessary conditions for it to occur will be presented before proceeding with the experimental section where phase transfer under overcharging conditions will be experimentally investigated. The presentation will focus on the adsorption of the hydrolyzed species rather than on the adsorption of surfactants. This latter step in the adsorption process has been extensively studied by others (see Fuerstenau and Colic, 1999 for a review and many references) and we have little to add on this topic.

\section{SHORT OVERVIEW ON ELECTRIC DOUBLE LAYERS AND OVERCHARGING}

\subsection{Double Layer Structure With Simple Inorganic Electrolytes}

Virtually all minerals acquire a surface charge when immersed in an aqueous electrolyte solution. The processes by which the surface charge is established may vary from system to system. Quite often the surface charge results from the ad/desorption of charge determining ions, which are ions that have a particularly high affinity for the surface and become part of the adsorbent after adsorption (Lyklema, 1991). Which ions are charge determining depends on the system under consideration. For AgI, for instance, $\mathrm{Ag}^{+}$and $\mathrm{I}^{-}$have been identified as charge determining and for $\mathrm{BaSO}_{4}, \mathrm{Ba}^{2+}$, and $\mathrm{SO}_{4}^{2-}$ are charge determining. In the case of (hydr-) oxides and and many silicates $\mathrm{H}^{+}$and $\mathrm{OH}^{-}$are charge determining and therefore the surface charge density can be changed by $\mathrm{pH}$ control. Typical reactions at the surface can be formulated as ad-/desorption equilibria:

$$
\begin{aligned}
& >\mathrm{ROH} \longleftrightarrow>\mathrm{RO}^{-}+\mathrm{H}^{+} \text {and } \\
& >\mathrm{ROH}+\mathrm{H}_{2} \mathrm{O} \longleftrightarrow>\mathrm{ROH}_{2}^{+}+\mathrm{OH}^{-}
\end{aligned}
$$

In this notation $>\mathrm{R}$ denotes an atom of the solid. The surface charge density $\sigma^{0}$ is defined as the difference between the surface excess of $\mathrm{H}^{+}$and $\mathrm{OH}^{-}$, which can be determined experimentally by potentiometric titrations. Only by such methods can a point of zero charge be established.
Once a surface has acquired a charge, the surface charge density has to be compensated in equal and opposite amount on the solution side of the surface: an electric double layer will form, whose detailed structure varies from system to system. In the easiest case the surface charge density will be entirely compensated by indifferent electrolytes, which, by definition, experience purely Coulombic attraction/repulsion from the surface (Lyklema, 1991). When this is the case, the electrical double layer is said to be entirely diffuse and the variation of the electrical potential perpendicular to the surface follows GouyChapman theory. The electroneutrality condition for such a double layer reads $\sigma^{0}+\sigma^{d}=0$, in which $\sigma^{d}$ is the charge density of the diffuse double layer. This parameter can be calculated via Gouy-Chapman theory if the diffuse layer potential is known. For a flat double layer in a symmetrical electrolyte diffuse layer charge density and potential are related by (Lyklema, 1995):

$$
\sigma^{d}=-\sqrt{8 \varepsilon \varepsilon_{0} c R T} \sinh \left(z y^{d} / 2\right)
$$

Here $\varepsilon \varepsilon_{0}$ is the dielectric constant of the solvent, $R$ the ideal gas constant, $T$ the temperature, $c$ the concentration of the electrolyte, $z$ the charge, and $y^{d}=F \psi^{d} / R T$. Note that the relationship between charge and potential of diffuse layer looks quite different when non-symmetrical electrolytes or electrolyte mixtures are considered.

In order to decide whether an electrolyte is truly indifferent or not, one has basically two options: (1) Measure either surface charge or diffuse layer charge density with electrolytes of the same charge but different nature and (2) measure the surface charge density and the diffuse layer charge density simultaneously. In the framework of option (1), an indifferent electrolyte would give the very same parameters for every electrolyte of the same charge. The more direct and quantitative option (2) allows testing of the electroneutrality condition. For an indifferent electrolyte this condition would always be fulfilled, implying that the point of zero charge ( $\mathrm{pH}$ at which $\sigma^{0}=0$ ) and the isoelectric point ( $\mathrm{pH}$ at which $\sigma^{d}=0$ ) coincide. Experimental evidence collected over the past decades shows that in many systems presumably indifferent electrolytes are not quite indifferent. Not only is this based on the shift of isoelectric points vs. points of zero charge, but violations of the simple electroneutrality condition have been observed as well (see for instance Lyklema, 1989, 1994). The basic tendency is $\left|\sigma^{0}\right|>\left|\sigma^{d}\right|$, which implies that there has to be another location where charges can accumulate in order for the double layer to be electroneutral.

Such observations, together with experimental evidence from electrokinetic studies (see Dukhin and Derjaguin, 1974; Hunter, 1981; Delgado et al., 2007), make the introduction of a Stern layer necessary, a modification of the diffuse double layer structure suggested by Stern (1924). The resulting double layer configuration is schematically shown in Figure $\mathbf{1 .}$

In this figure there is a negatively charged surface with charge density $\sigma^{0}$ and associated surface potential $\psi^{0}$. The region between the surface and the inner Helmholtz plane (iHp), where the electric potential is $\psi^{i}$, is charge free. The iHp is the plane where specifically adsorbed ions reside (creating a charge density $\sigma^{i}$ ) and its distance to the surface is often said to be 


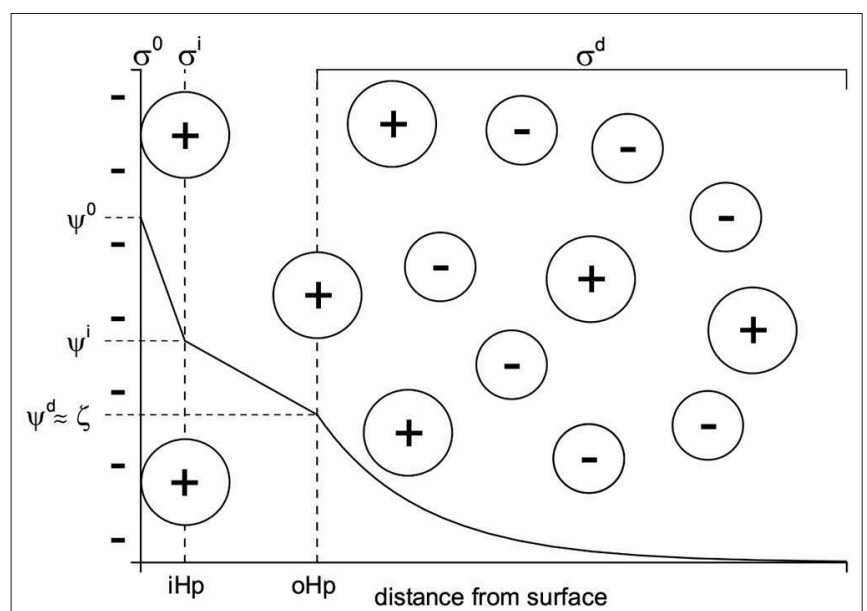

FIGURE 1 | Schematic model of the electric double layer including a Sternand a diffuse layer.

determined by the size of the specifically adsorbed species. Note that specifically adsorbing ions experience, in addition to the purely electrostatic attraction, additional attraction to the surface. Due to the additional force(s) operating at the iHp equations like Eq. 1 that only consider an electrical attraction/repulsion no longer hold in this region of the double layer. For the charge density $\sigma^{i}$ one has to formulate an adsorption isotherm. Among the many options to do so, we quote Hunter and Wright (1971):

$$
\sigma^{i}=z_{i} e N_{s} e^{-\left(z_{i} e \psi^{i}+\Delta G_{n e}\right) / k T}
$$

Here $e$ is the elementary charge, $\psi^{i}$ the electric potential at the iHp, $k$ Boltzmann's constant, $\Delta G_{n e}$ a specific adsorption free energy and $N_{s}$ the site density available for specific adsorption, which is not necessarily the same as the total number of surface sites. The specific adsorption free energy simply reflects the additional work terms that are needed to bring an ion from the free solution to the $\mathrm{iHp}$ and is of a nonelectric nature. Examples include solvent structure mediated interactions, complex formation or hydrophobic bonding.

Going further to the solution side of the double layer, there is again a charge free region up to the outer Helmholtz plane (oHp). In Figure 1 we have not made a distinction between the oHp and the slip plane. Consequently the electrical potentials $\psi^{d}$ and $\zeta$ are approximated to be equal. For a discussion on the positioning of the slip plane relative to the oHp and the distinctions between $\psi^{d}$ and $\zeta$ we refer to Lyklema (2011) and Hunter (1981). The oHp, no matter if equated to the slip plane or not, marks the start of the diffuse part of the double layer, where the Gouy-Chapman theory applies. The electroneutrality condition for such a double layer reads $\sigma^{0}+\sigma^{i}+\sigma^{d}=0$.

This picture of the double layer, although physically not the most precise, is sufficiently simple and able to account for many experimental results.

\subsection{Overcharging}

The phenomenon of overcharging describes a situation in which the addition of an electrolyte containing multivalent counterions

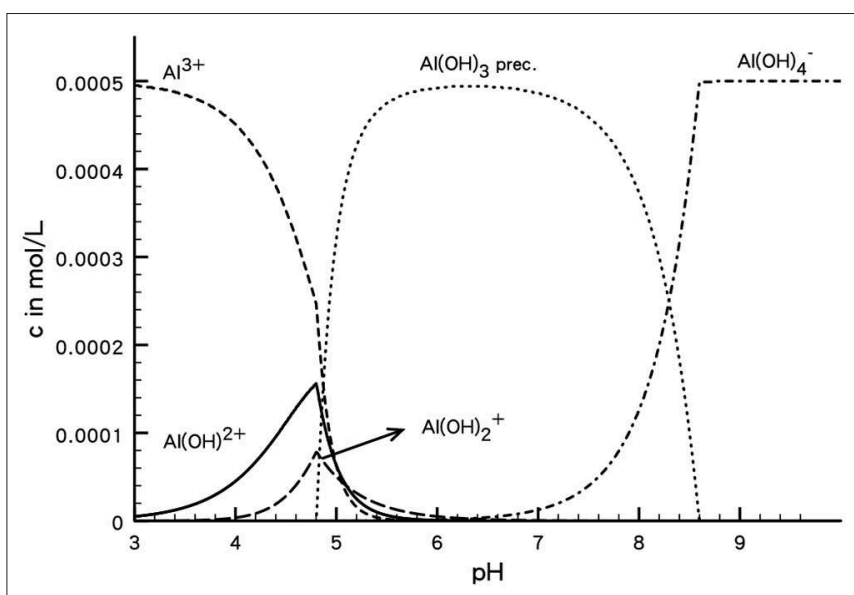

FIGURE 2 | Speciation of $\mathrm{Al}$ in $0.5 \mathrm{mM} \mathrm{AlCl}_{3}$ solution, assuming that all $\mathrm{Al}$ available can be precipitated into amorphous $\mathrm{Al}(\mathrm{OH})_{3}$. Only dominant species are shown.

can lead to a sign reversal of the $\zeta$-potential, which is not induced by $\mathrm{pH}$ changes. Note that overcharging is also called charge reversal, electrokinetic charge inversion and superequivalent adsorption. There are two popular explanations that may account for this: ion-ion correlations and a drastic specific adsorption of certain species within the Stern layer. Both of these options are discussed in Jiménez et al. (2012) and Lyklema (2009) where many references can be found. Briefly one may state that ion correlation theories require simultaneously high surface charge densities and high concentrations of multivalent counterions. Experimentally such situations have been observed in surface force studies (e.g., Kekicheff et al., 1993).

With respect to specific adsorption, the observation is that multivalent electrolytes that tend to form hydrolysis species can reverse the sign of the $\zeta$-potential at rather low concentrations and often at quite low surface charge densities ${ }^{1}$ (e.g., Matijević et al., 1962, 1964, 1971; James and Healy, 1972; James et al., 1977; Lyklema and Golub, 2007; Jiménez et al., 2012). The usual reasoning is that such hydrolysis products appear to have a rather high affinity for specific adsorption at the iHp. This statement derives from the fact that the effect is usually only observed in a limited $\mathrm{pH}$ window for a given electrolyte.

As an example one may consider the speciation in an $\mathrm{AlCl}_{3}$ solution as a function of $\mathrm{pH}$ (Figure 2). The calculations have been performed with ChemEQL (Mueller, 1996) assuming that all the available $\mathrm{Al}$ can be precipitated as amorphous $\mathrm{Al}(\mathrm{OH})_{3}$. Immaterial of this assumption one can see that at acidic $\mathrm{pH}$ values hydrolyzed species are present and that not all the $\mathrm{Al}$ in the system is trivalent. At about $\mathrm{pH}=5$ the precipitation of $\mathrm{Al}(\mathrm{OH})_{3}$ sets in and in the alkalic range the dominant species in $\mathrm{Al}(\mathrm{OH})_{4}^{-}$.

For aluminum chloride and nitrate solutions it was indeed observed that overcharging will only occur in the acidic range, being most effective around $\mathrm{pH}=4-5$. Such reasoning is of course applicable to many other electrolytes that form hydrolyzed ${ }^{1}$ Depending on the system just some $10-100 \mu \mathrm{mol} / \mathrm{L}$ and charge densities $\mathcal{O}\left(10^{0}\right)$
$\mu \mathrm{C} / \mathrm{cm}^{2}$ are sufficient. 

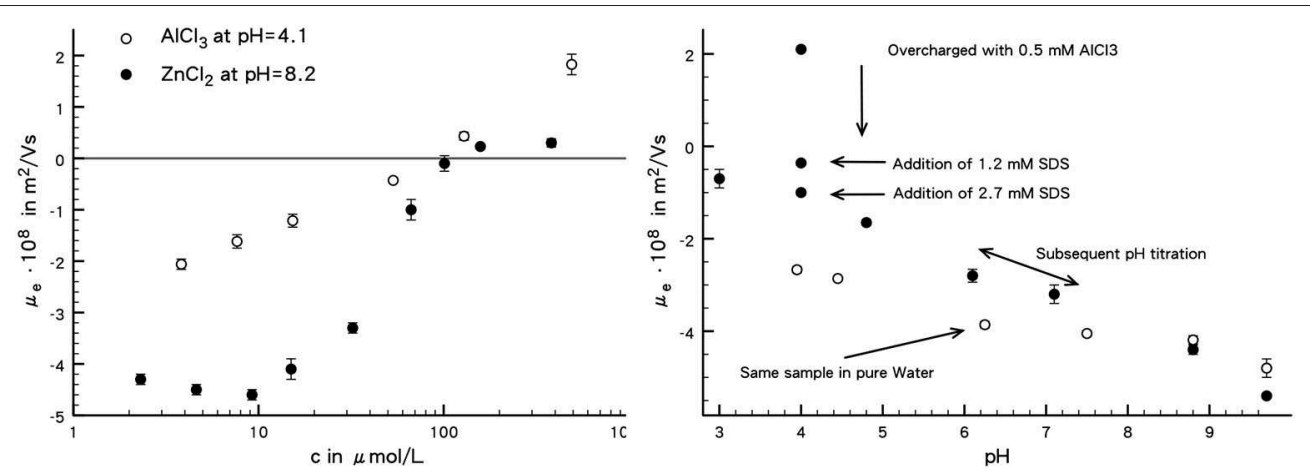

FIGURE 3 | (Left) electrophoretic mobility of SFP-30M as a function of $\mathrm{AlCl}_{3}$ at $\mathrm{pH}=4.1$ and $\mathrm{ZnCl}_{2}$ at $\mathrm{pH}=8.2$. (Right) electrophoretic mobility of SFP-30M in pure water (open circles) and of the same sample at $\mathrm{pH}=4$ (full circles), overcharged with $0.5 \mathrm{mM} \mathrm{AlCl} 3$. To this sample SDS was added with a subsequent pH titration. See text for detailed explanation. The error bars represent the standard deviation from three measurements.

species in other $\mathrm{pH}$ ranges and was observed for many different solids. This suggests that the phenomenon as such is quite generic. A further discussion of overcharging will be given at the end of the article.

An important point to make is, that the effect does not mean that the sign of the surface charge density changes, it is the diffuse layer charge density that changes sign (see Lyklema and Golub, 2007 for comprehensive experimental evidence). At a given concentration of electrolyte the surface charge density is determined by the $\mathrm{pH}$ in the case of oxides. If there is more specific adsorption at the iHp than is needed to compensate the surface charge, electroneutrality dictates that the diffuse layer charge density has to change sign, which is experimentally observed as a change in sign of the $\zeta$-potential.

To promote overcharging, one has to look for multivalent electrolytes that form hydrolyzed species in aqueous solution. Popular candidates include $\mathrm{Al}(\mathrm{III}), \mathrm{La}(\mathrm{III}), \mathrm{Fe}(\mathrm{III})$, and $\mathrm{Zn}$ (II) chlorides and nitrates. Typically, there will be certain $\mathrm{pH}$ windows where hydrolyzed species are stable and these are precisely the $\mathrm{pH}$ ranges one wishes to investigate for overcharging.

\section{MATERIALS AND METHODS}

The experiments reported in here have been conducted with a commercial spherical silica (SFP-30M from Denka, Japan). According to the manufacturer, the particle size is in the range between 0.1 and $2 \mu \mathrm{m}$ with a median diameter of $0.6 \mu \mathrm{m}$ and the specific surface area of the sample is $5.6 \mathrm{~m}^{2} / \mathrm{g}$.

The chemicals used in the experiments have been used without further purification. The purity of the metal chlorides was at least 99\% [CAS Numbers: 7784-13-6 $\left.\left(\mathrm{AlCl}_{3}\right), 7646-85-7\left(\mathrm{ZnCl}_{2}\right)\right]$, n-Hexane (CAS Number: 110-54-3) was obtained from Merck as chromatographic grade and SDS was also obtained from Merck with a quoted homologue $\mathrm{C}_{12}$ purity of $\geq 98 \%$ (CAS Number: 151-21-3).

Electrophoretic mobilities were measured with a Malvern Zetasizer Nano in folded capillary cells. The suspension has been stirred in a double-walled glass vessel that was connected to a water thermostad. Measurements have been carried out at $25^{\circ} \mathrm{C}$ with a drive voltage of max. $40 \mathrm{~V}$. For each point 3 measurements have been made, each consisting of 50-100 sub runs.

Phase transfer experiments have been conducted in the following manner: An aqueous stock suspension was prepared with the desired concentration of a given metal salt, after which $2 \mathrm{~g} / \mathrm{L}$ silica were immersed in the solution. This suspension was then sonicated for $\approx 2 \mathrm{~min}$ in order to properly disperse the particles. The desired amount SDS was added to this suspension in dry form. Different $\mathrm{pH}$ values were then adjusted by the addition of $\mathrm{HCl}$ or $\mathrm{NaOH}$. For each tube $20 \mathrm{~mL}$ of aqueous suspension were withdrawn and $5 \mathrm{~mL}$-Hexane were added. These tubes were then shaken in order to observe whether a successful phase transfer is accomplished.

The transmittance (relative to pure water) of the aqueous phase was measured with an Agilent Technologie Cary 60 UV-Vis spectrometer at $800 \mathrm{~nm}$ in order to obtain a qualitative indication of the efficiency of the phase transfer.

\section{RESULTS AND INTERPRETATION}

The electrophoretic mobilities $\left(\mu_{e}\right)$ measured in different electrolyte solutions and in pure water are shown in Figure 3. Absolute electrophoretic mobilities will be used in discussing trends of this quantity.

First of all it is noted that the electrophoretic mobility in pure water is negative in the entire $\mathrm{pH}$ range studied. This is usual for silica and crystalline $\mathrm{SiO}_{2}$ phases. Although the surface charge density is not at our disposal for this specific sample, it seems reasonably safe to say that the point of zero charge is not reached for the sample since there is rather good agreement in the literature that silicas have points of zero charge below $\mathrm{pH}=3$ if one is found at all (see Lyklema, 1995).

Based on the speciation of $\mathrm{AlCl}_{3}$ and $\mathrm{ZnCl}_{2} \mathrm{pH}$ ranges were selected where overcharging can be suspected to occur. For aluminum chloride this is in the acidic range (roughly $\mathrm{pH}=4$ 5 ) and for zinc chloride this is in the alkalic range (roughly $\mathrm{pH}$ $=8-9$ ). Suspension were prepared with the desired $\mathrm{pH}$ and a titration with the corresponding electrolyte was conducted (see Figure 3, left). For aluminum chloride a steady increase of the electrophoretic mobility is observed and a change in its sign 

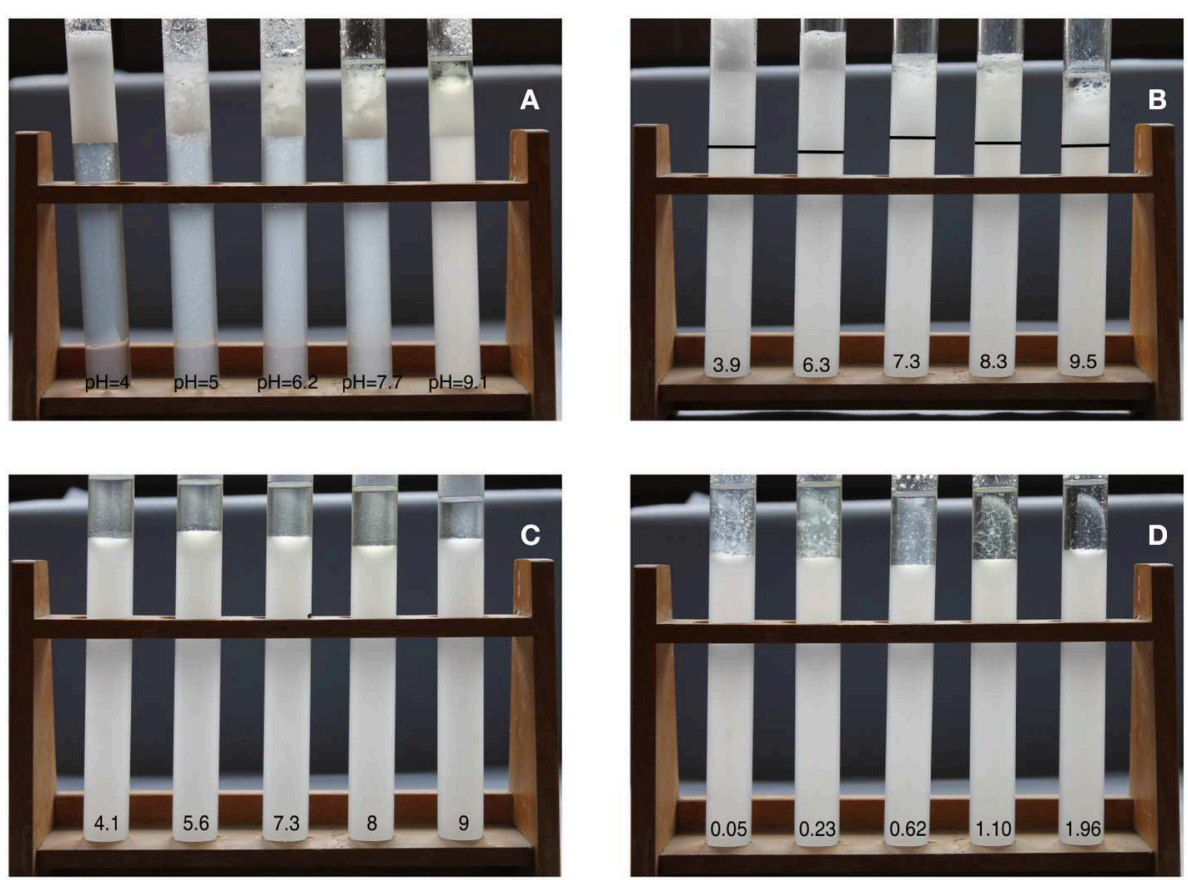

FIGURE 4 | Pictures of the phase transfer experiments. (A) $0.5 \mathrm{mM} \mathrm{AlCl}_{3}$ with $2 \mathrm{mM} \mathrm{SDS}$, (B) $\mathrm{ZnCl}_{2}$ with $2 \mathrm{mM} \mathrm{SDS}$, (C) $0.5 \mathrm{mM} \mathrm{CaCl}$ with $2 \mathrm{mM} \mathrm{SDS}$ and (D) 11 $\mu \mathrm{mol} \mathrm{AlCl}_{3}$ at $\mathrm{pH}=4.6$ with different SDS concentrations. $\mathrm{pH}$ values in (A-C) are indicated and the SDS concentration in (D) is given in $\mathrm{mM}$.

occurs at $\approx 0.1 \mathrm{mM}$. Upon further addition of electrolyte the mobility increases further, which indicates that the adsorption in the Stern layer is not completed after the change of sign.

The mobilities of zinc chloride suspensions are somewhat more complicated. At rather low concentration a decrease in mobility is noted. This is a definitive hint for Stern layer adsorption in conjunction with mobile ionic species in this part of the double layer. Such mobility maxima are observed on a standard basis in electrokinetic studies and can be traced back to surface conductance in the Stern layer (Delgado et al., 2007). Upon further addition of electrolyte, the mobility starts to increase rapidly and eventually changes sign at about $0.1 \mathrm{mM}$. Further addition of electrolyte does not change the mobility markedly anymore which can be taken as a sign that Stern layer adsorption of this species is completed.

Now that the solution compositions for overcharging are established, SDS was added to a suspension overcharged with 0.5 $\mathrm{mM} \mathrm{AlCl}_{3}$ at $\mathrm{pH}=4$ was measured (see Figure 3, right). The first addition of $1.2 \mathrm{mM}$ SDS decreases the mobility from initially $2 \cdot 10^{-8} \mathrm{~m}^{2} / \mathrm{Vs}$ to about $-0.5 \cdot 10^{-8} \mathrm{~m}^{2} / \mathrm{Vs}$. Further addition of SDS (equivalent to $2.7 \mathrm{mM}$ ) decreases the mobility further to $\approx-1 \cdot 10^{-8} \mathrm{~m}^{2} / \mathrm{Vs}$. This can be taken as an indication that the adsorbed aluminum species act as adsorption sites for the negative part of the SDS. In order to investigate the stability of these Stern layer species, a $\mathrm{pH}$ titration was carried out after the addition of $2.7 \mathrm{mM}$ SDS. The general shape of the mobility vs. $\mathrm{pH}$ curve is quite similar to the one recorded in pure water. $\mathrm{Up}$ to $\mathrm{pH} \approx 9$ the absolute mobilities in the SDS system are lower that those of pure water and in the alkalic range they do not differ too much from each other.
Furthermore, it is interesting to note that the $\mathrm{pH}$ titration is reversible.

Figure 4 shows the results of the qualitative phase transfer experiments. The lower phase is the aqueous phase and the upper one is n-Hexane. It can immediately be concluded that the success of the phase transfer depends on the type and concentration of the electrolyte and the $\mathrm{pH}$.

The transmittance measurements of the aqueous parts of these systems are presented in Figure 5. Note that these measurements should be interpreted qualitatively, because in $\mathrm{AlCl}_{3}-\mathrm{SDS}$ systems precipitation of a Al-SDS phase occurs which will be discussed later.

Even without a detailed mechanistic explanation one can conclude from Figures 4, 5 that the phase transfer in the system containing $0.5 \mathrm{mM} \mathrm{AlCl} 3$ with $2 \mathrm{mM}$ SDS is most effective. Within this system there is a pronounced $\mathrm{pH}$ dependency of the transfer efficiency as indicated by the transmission measurements. At low $\mathrm{pH}$, where overcharging is most pronounced, the phase transfer is almost complete, decreasing toward the alkalic range where a quite low amount of particles is transferred. Considering the system with $11 \mu \mathrm{mol} / \mathrm{L} \mathrm{AlCl}_{3}$ at $\mathrm{pH}=4.6$, where the $\mathrm{Al}$ concentration is too low to overcharge the silica, one cannot observe a phase transfer at all, immaterial of the SDS concentration. In the $\mathrm{ZnCl}_{2}$ system one observes a partial, but $\mathrm{pH}$ independent phase transfer. As a comparison to this system, we have conducted the same experiment with $\mathrm{CaCl}_{2}$, which does not hydrolyze significantly in the studied $\mathrm{pH}$ range and does not cause overcharging. No phase transfer at all is observed in this system. All these observations, although largely qualitative, show that overcharging is a necessary condition 


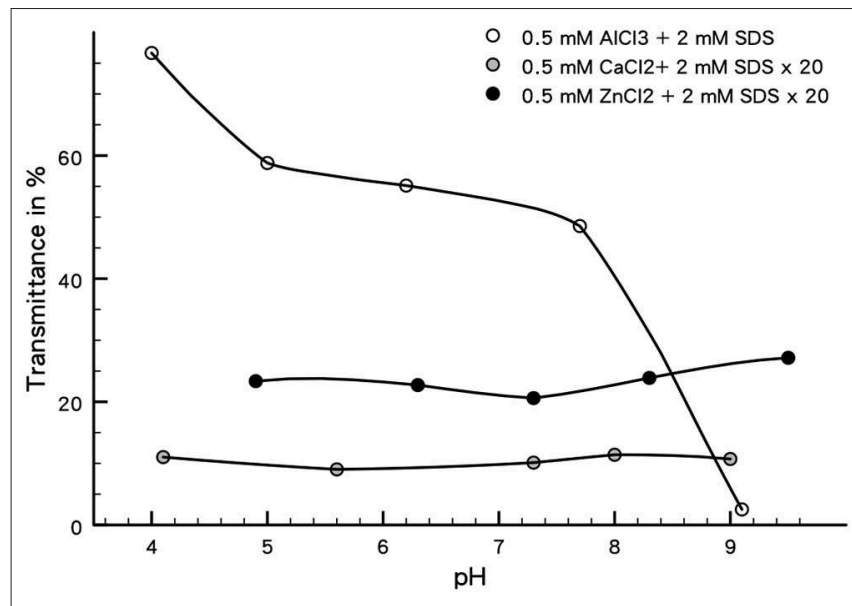

FIGURE 5 | Transmittance (at $800 \mathrm{~nm}$ ) of the aqueous phase of the phase transfer experiments shown in Figure 4. Note that the data for $0.5 \mathrm{mM} \mathrm{CaCl}_{2}$ and $\mathrm{ZnCl}_{2}$ have both been multiplied by a factor of 20 in order to make them visible with respect to the $\mathrm{AlCl}_{3}$ system.

for a successful phase transfer in our system. The following section is intended to provide a more detailed explanation for these observations.

\section{DISCUSSION}

Before discussing the details of overcharging and the subsequent adsorption of $\mathrm{DS}^{-}$, it is necessary to point out that we have observed the formation of a precipitate in solutions of $\mathrm{AlCl}_{3}$ and SDS. Visually this can be observed at a ratio of SDS/ $\mathrm{AlCl}_{3}$ $\approx 1$. Upon further addition of SDS the precipitation proceeds until a ratio of $\mathrm{SDS} / \mathrm{AlCl}_{3} \approx 12$ is attained, where the solution is entirely transparent again. This effect is known for $\mathrm{AlCl}_{3}$ sulfonate systems (Somasundaran et al., 1988) and goes by the name precipitation-redissolution phenomena. In the $\mathrm{Al}\left(\mathrm{NO}_{3}\right)_{3}$ dodecylsulfate system similar observations have been made (Pereira et al., 2009). Regardless of the specific details of these processes, it must be noted that our $\mathrm{AlCl}_{3}$ experiments have been conducted in a concentration range $\left(\mathrm{SDS} / \mathrm{AlCl}_{3}=4\right)$ where precipitation occurs. It is therefore logical to question whether the successful phase transfer is due to the presence of the precipitate or due to the effect of overcharging with concomitant adsorption of $\mathrm{DS}^{-}$. It is for this reason that we have conducted the same experiments with a lower concentration of $\mathrm{AlCl}_{3}$, where overcharging does not occur. In these experiments the SDS concentration was varied to cover a range of SDS/ $\mathrm{AlCl}_{3}=4-178$, where both precipitation and redissolution occur.

As mentioned in the previous section, no phase transfer was observed in these experiments. This suggests that overcharging is the dominating mechanism leading to the adsorption of $\mathrm{DS}^{-}$. To see this point, consider the experiments with $\mathrm{ZnCl}_{2}$ and $\mathrm{CaCl}_{2}$. Here we observe no phase transfer for $\mathrm{CaCl}_{2}$, but observe a partial one for $\mathrm{ZnCl}_{2}$. This is due to the ability of $\mathrm{Zn}$ to overcharge the silica at alkalic $\mathrm{pH}$, whereas $\mathrm{Ca}$ is not able to do so at such low concentration. Furthermore, we have not observed (visually) a precipitation of $\mathrm{ZnCl}_{2}+\mathrm{SDS}$ solutions.

The experimental data presented in here and the numerous experimental observations cited in conjunction with the overcharging phenomenon demonstrate that the sign reversal of the electrophoretic mobility is at least in part due to the specific adsorption of hydrolyzed species. One may now wonder why such hydrolyzed species, which have a lower charge than the unhydrolyzed metal cation, adsorb so effectively.

In addition to the electrostatic adsorption energy at the $\mathrm{iHp}$, which is $\Delta G_{e l}=z e \psi^{i}$, one may quite generally add a solvation term (see for instance James and Healy, 1972). The free energy change associated with ion solvation describes the process of transferring an ion from a region of high dielectric constant to a region of lower dielectric constant. These authors derived a relationship for the solvation work required to bring an ion from the free solution to the iHp:

$$
\begin{aligned}
\Delta G_{\text {solv }} & =\left(\frac{z_{i}^{2} e^{2}}{16 \pi \varepsilon_{0}}\right)\left(\frac{1}{r_{i}+2 r_{w}}-\frac{r_{i}}{2\left(r_{i}+2 r_{w}\right)^{2}}\right)\left(\frac{1}{\varepsilon_{i H p}}-\frac{1}{\varepsilon_{w}}\right) \\
& +\left(\frac{z_{i}^{2} e^{2}}{32 \pi \varepsilon_{0}}\right)\left(\frac{1}{r_{i}+2 r_{w}}\right)\left(\frac{1}{\varepsilon_{s}}-\frac{1}{\varepsilon_{i H p}}\right)
\end{aligned}
$$

In this relation $z_{i}$ is the charge of the ions, $e$ the elementary charge, $\varepsilon_{0}$ the permitivitty of free space, $\varepsilon_{w}$ the relative dielectric constant of water, $\varepsilon_{s}$ the one of the solid, $\varepsilon_{i H p}$ the effective relative dielectric constant at the iHp, $r_{i}$ the radius of the ion and $2 r_{w}$ the diameter of a water molecule. Note that James and Healy (1972) place the iHp at a distance $2 r_{w}+r_{i}$ away from the surface. The difficult point is to define and calculate reasonable values for the dielectric constant at the iHp, since at such small length scales a definition of a macroscopic quantity becomes somewhat ambiguous. James and Healy (1972) chose to relate this dielectric constant to the field strength in the double layer. This step, however, is somewhat inconsistent, because diffuse double layer theory is applied up to the $\mathrm{iHp}$ in order to obtain the required relationship. Moreover, the change of dielectric constant close to a solid surface is a general property of structurable solvents. This is why we choose a relationship suggested by Podgornik et al. (1987) to construct the dielectric profile:

$$
\varepsilon_{w}(x)=\frac{\varepsilon_{w}}{1+\left(\varepsilon_{w} / \varepsilon_{s}-1\right) e^{-x / l}}
$$

where $x$ is the distance to the solid surface and $l$ the correlation length of water. Last but not least, James and Healy (1972) added a chemical contribution to the adsorption free energy. This chemical contribution embraces all specific interactions that may occur in the system and, just like the electrical contribution, it is a favorable energy change. It is furthermore assumed that this term is constant and applies to all species present. Within this simple model the total adsorption free energy at the $\mathrm{iHp}$ is written as the sum of the discussed contributions: $\Delta_{a d s} G=\Delta G_{e l}+$ $\Delta G_{\text {solv }}+\Delta G_{\text {chem }}$. An example calculation along these lines is shown in Figure 6. The parameters chosen for the calculation are 


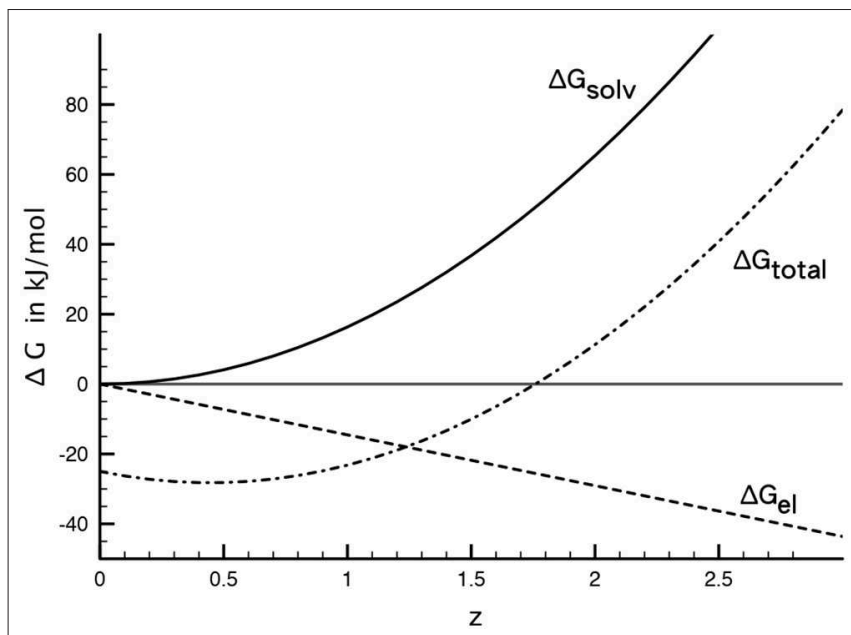

FIGURE 6 | Solvation and electrostatic contribution to total free energy of adsorption in the Stern layer. For parameters see text. The chemical contribution of $\Delta G_{c h e m}=-25 \mathrm{~kJ} / \mathrm{mol}$ (not shown) is added to the total adsorption free energy.

as follows: As already mentioned above, the position of the $\mathrm{iHp}$ is fixed as $2 r_{w}+r_{i}$, where $2 r_{w}=0.284 \mathrm{~nm}$ and $r_{i}=0.05 \mathrm{~nm}\left(\mathrm{Al}^{3+}\right)$ (Marcus, 1988). The dielectric constant of $\mathrm{SiO}_{2}$ has be taken as $\varepsilon_{s}$ $=4$ (Hunter, 2000) and the correlation length of water has been set to $2 r_{w}=0.284 \mathrm{~nm}$. With these values the dielectric constant at $2 r_{w}+r_{i}=0.33 \mathrm{~nm}$ is $\varepsilon_{i H p}=10$. Finally the electric potential at the iHp has ben set $\psi^{i}=-0.15 \mathrm{~V}$ and the chemical part of the adsorption free energy has been chosen as $\Delta G_{\text {chem }}=-25 \mathrm{~kJ} / \mathrm{mol}$ (an intermediate value from James and Healy, 1972).

It can be seen that the electrical and chemical contributions represent a favorable energy change, i.e., they promote adsorption. While the chemical part has, as usual, been assumed constant, the electrical part increases lineraly with $z$. The energy penalty represented by the solvation term, however, scales with $z^{2}$. It thus represents an energy barrier for the adsorption of higher-valence ions. In the example presented here, the adsorption would be favorable for species with $z \lesssim 2$.

Due to the quite large number of unknown parameters such calculations should not be taken as quantitative unless more experimental data is available. They do, however, highlight the decisive role of solvation in the adsorption of hydrolyzed species. James and Healy (1972) used a similar approach to fit adsorption isotherms in such systems and were able to describe their experimental results with reasonable parameter choices. The difference being that they related the dielectric constant to the field strength in the double layer (see above). The simple treatment of the dielectric constant profile presented above is somewhat more attractive in that it does not involve the application of Gouy-Chapman theory in the inner part of the double layer and that it is applicable to structurable solvents in general.

The $\mathrm{pH}$ titration of overcharged $\mathrm{SiO}_{2}$ in the presence of 2.7 $\mathrm{mM}$ SDS shown in Figure 3 is reversible with respect to $\mathrm{pH}$ changes. This is an important observation, because it shows that the Al-DS ${ }^{-}$complexes are adsorbed quite strongly in the Stern layer. When SDS is added to the overcharged silica, part of the SDS adsorbs to the positive Al sites in the Stern layer. The amount of SDS added in our system is high enough to reverse the overcharging, meaning that $\left|\sigma^{0}\right|>\left|\sigma^{i}\right|$, which is indicated by the electrophoretic mobility going to negative values again. The fact that at $\mathrm{pH}=4$ the mobility remains well above the mobility of the sample in water suggests that there is still a finite charge density located in the Stern layer when $\mathrm{AlCl}_{3}$ and SDS are added. If this charge density is more or less $\mathrm{pH}$-independent, a titration to high $\mathrm{pH}$ will increase the surface charge density $\sigma^{0}$ while $\sigma^{i}$ remains more or less constant. At alkalic $\mathrm{pH} \sigma^{0}$ becomes eventually so large that that the contribution of $\sigma^{i}$ becomes less notable and similar diffuse layer charge densities are obtained again (with respect to the pure water case). This is precisely what can be observed from the electrophoretic mobilities.

Moreover it was observed that the phase transfer as such is reversible. In the presence of $0.5 \mathrm{mM} \mathrm{AlCl}_{3}+2 \mathrm{mM}$ SDS at $\mathrm{pH}$ $=4$, a rather effective phase transfer is observed (see Figures 4, 5). When $\mathrm{NaOH}$ is added to the aqueous phase and the tube is shaken again, most of the particles are transferred to the aqueous phase again. This is a remarkable observation, for which we do not have a definitive explanation up to now.

Apart from the energetic changes occurring at the aqueoussolid interface it is also permissible that the interface tension of the aqueous-Hexane interface is influenced by the precipitates in the $\mathrm{AlCl}_{3}$-SDS system. Preliminary measurements indicate that at acidic $\mathrm{pH}$ the interface tension is lower at acidic $\mathrm{pH}$ than at alkalic $\mathrm{pH}$, which can also contribute to the efficiency of the phase transfer. Altogether these results show that the systems studied here are quite complicated ones and that multiple adsorption processes at different interfaces as well as the liquid chemistry as such deserve further attention.

\section{CONCLUSION}

Using electrophoresis measurements and phase transfer experiments it was shown that overcharging by hydrolyzed metal species is responsible for the adsorption of an anionic collector (SDS) to a negatively charged surface. The phase transfer, and thus the hydrophobization of particles, was found to be most effective when overcharging is most pronounced. The complicated interactions between SDS and multivalent cations, however, hamper an in-depth understanding of the multiple adsorption phenomena at the different interfaces.

What appears to be established is that overcharging by hydrolyzed species is a necessary condition for a phase transfer in our systems. The processes leading to overcharging by inorganic ions were discussed an it was emphasized that ion solvation can play a decisive role by creating an energetic barrier for the adsorption of multivalent ions.

\section{DATA AVAILABILITY STATEMENT}

All datasets generated for this study are included in the article/supplementary material. 


\section{AUTHOR CONTRIBUTIONS}

CW designed, conducted, and interpreted the experiments. UP designed experiments and critically examined the results.

\section{FUNDING}

CW appreciates funding by the DFG (SPP2045, 313858373).

\section{REFERENCES}

Delgado, A. V., Gonzalez-Caballero, F., Hunter, R., Koopal, L. K., and Lyklema, J. (2007). Measurement and interpretation of electrokinetic phenomena. J. Colloid Interface Sci. 209, 194-224. doi: 10.1016/j.jcis.2006.12.075

Dukhin, S. S., and Derjaguin, B. V. (1974). "Chapter 2: Electrokinetic phenomena," in Surface and Colloid Science, ed V. Matijević (New York, NY: John Wiley and Sons), 356.

Fuerstenau, D. W., and Colic, M. (1999). Self-association and reverse hemimicelle formation at solid-water interfaces in dilute surfactant solutions. Colloids Surfaces A Physicochem. Eng. Aspects 146, 33-47. doi: 10.1016/S0927-7757(98)00795-X

Furstenau, D. W., and Pradip (2005). Zeta potentials in the flotation of oxide and silicate minerals. Adv. Colloid Interface Sci. 9-26, 114-115. doi: 10.1016/j.cis.2004.08.006

Furstenau, M. C., Rice, D. A., Somasundaran, P. and Furstenau, D. W. (1965). Metal ion hydrolysis and surface charge in beryl flotation. Trans. Am. Inst. Mining Metallur. Eng. 74, 381-391.

Hunter, R. (1981). "Zeta potential in colloid science - Principles and applications," in Colloid Science: A Series of Monographs, eds R. H. Ottewill and R. L. Rowell (London: Academic Press), 386.

Hunter, R. (2000). Foundations of Colloid Science, 2nd Edn. New York, NY: Oxford University Press Press,

Hunter, R., and Wright, H. J. L. (1971). The dependence of electrokinetic potential on concentration of electrolyte. J. Colloid Interface Sci. 37, 564-580. doi: 10.1016/0021-9797(71)90334-1

James, R. O., and Healy, T., W. (1972). Adsorption of hydrolyzable metal ions at the oxide-water interface iii. a thermodynamic model of adsorption. J. Colloid Interface Sci. 40, 65-81. doi: 10.1016/0021-9797(72)90174-9

James, R. O., Wiese, G. R., and Healy, T., W. (1977). Charge reversal coagulation of colloidal dispersions by hydrolysable metal ions. J. Colloid Interface Sci. 59, 381-385. doi: 10.1016/0021-9797(77)90023-6

Jiménez, M. L., Delgado, A. V., and Lyklema, J. (2012). Hydrolysis versus ion correlation models in electrokinetic charge inversion: establishing application ranges. Langmuir 28, 6786-6793. doi: 10.1021/la3010773

Kekicheff, P., Marcelja, S., Senden, T. J., and Shubin, V. E. (1993). Charge reversal seen in electrical double layer interaction of surfaces immersed in 2:1 calcium chloride solutions. J. Chem. Phys. 99, 6098-6113.

Leistner, T., Müller, M., Erler, J. V., Rudolph, M., and Peuker, U. A. (2014). Selektive trennung sehr feiner partikelsysteme mittels flüssig/flüssig-flotation. Chem. Ingenieur Technik 86, 831-839. doi: 10.1002/cite.201400011

Leistner, T., Türk, M., Weber, A., Weber, C., and Peuker, U. A. (2019). Selective separation using fluid-liquid interfaces. Mater. Sci. Forum 959, 113-124. doi: 10.4028/www.scientific.net/MSF.959.113

Lyklema, J. (1989). Discrimination between physical and chemical adsorption of ions on oxides. Colloids Surfaces 37, 197-204. doi: 10.1016/0166-6622(89)80118-0

Lyklema, J. (1991). Electrified interfaces in aqueous dispersions of solids. Pure Appl. Chem. 61, 895-906.

Lyklema, J. (1994). On the slip process in electrokinetics. Colloids Surfaces A Phys. Eng. Aspects 92, 41-49. doi: 10.1016/0927-7757(94)02727-7

Lyklema, J. (1995). Fundamentals of Interface and Colloid Science - Volume II: Solid-Liquid Interfaces. London: Academic Press.

Lyklema, J. (2006). Overcharging, charge reversal: chemistry or physics. Colloids Surfaces A Phys. Eng. Aspects 291, 3-12. doi: 10.1016/j.colsurfa.2006.06.043

\section{ACKNOWLEDGMENTS}

CW acknowledges insightful discussions with Dr. Martin Rudolph and Edgar Schach (HelmholtzZentrum Dresden-Rossendorf). Paul Knüpfer and Klaus Graebe are thanked for experimental assistance and B. von Klitzing from Denka for supply of the silica.

Lyklema, J. (2009). Quest for ion-ion correlations in electric double layers and overcharging phenomena. Adv. Colloid Interface Sci. 147-148, 205-213. doi: $10.1016 /$ j.cis.2008.12.002

Lyklema, J. (2011). Surface charges and electrokinetic charges: Distinctions and juxtapositionings. Colloids Surfaces A Phys. Eng. Aspects 376, 2-8. doi: $10.1021 /$ jp057096

Lyklema, J. (2013). Coagulation by multivalent counterions and the schulzehardy rule. J. Colloid Interface Sci. 392, 102-104. doi: 10.1016/j.jcis.2012. 09.066

Lyklema, J., and Golub, T. (2007). Electrical double layer on silver iodide and overcharging in the presence of hydrolyzable cations. Croatica Chem. Acta 80, 303-311.

Machunsky, S., Grimm, P., Schmid, H. J., and Peuker, U. A. (2009). Liquid-liquid phase transfer of magnetite nanoparticles. Colloids Surfaces A Phys. Eng. Aspects 348, 186-190. doi: 10.1016/j.colsurfa.2009. 07.014

Marcus, Y. (1988). Ionic radii in aqueous solution. Chem. Rev. 88, 1475-1498. doi: 10.1021/cr00090a003

Matijević, E., Janauer, G. E., and Kerker, M. (1964). Reversal of charge of lyophobic colloids by hydrolyzed metal ions i. aluminum nitrate. J. Colloid Interface Sci. 19, 333-346. doi: 10.1016/0095-8522(64) 90035-2

Matijević, E., Mangravite, F. J., and Cassell, E. A. (1971). Stability of colloidal silica iv. the silica-alumina system. J. Colloid Interface Sci. 35, 560-568. doi: 10.1016/0021-9797(71)90214-1

Matijević, E., Mathai, K. G., and Kerker, M. (1962). Detection of metal ion hydrolysis by coagulation v. zirconium. J. Phys. Chem. 66, 1799-1803. doi: $10.1021 / \mathrm{j} 100816 \mathrm{a} 006$

Mueller, B. (1996). ChemEQL. A Program to Calculate Chemical Speciation and Chemical Equilibria. Eidgenössische Anstalt für Wasserversorgung.

Pereira, R. F. P., Valente, A. J. M., Burrows, H. D., Ramos, M. L., Ribeiro, C. F., and Lobo, V. M. M. (2009). Flocculation and micellization of sodium dodecyl sulfate solutions in the presemce of aluminum nitrate: effect of concentration and temperature. Acta Chim. Slovenica 56, 45-52.

Podgornik, R., Cevc, G., and Zeks, B. (1987). Solvent structure effects in the macroscopic theory of van der waals forces. J. Chem. Phys. 87, 5957-5967. doi: $10.1063 / 1.453519$

Schubert, H. (1996). Aufbereitung Fetster Stoffe Band II: Sortierprozesse. Stuttgart: Deutscher Verlag für Grundstoffindustrie Stuttgart.

Somasundaran, P., Ananthapadmanabhan, K. P., and Celik, M. S. (1988). Precipitation-redissolution phenomena in sulfonate-alcl 3 solutions. Langmuir 4, 1061-1063.

Stern, O. (1924). Zur theorie der elektrolytischen doppelschicht. Zeitschrift für Elektrochemie und Angewandte Physikalische Chemie 30, 508-516.

Conflict of Interest: The authors declare that the research was conducted in the absence of any commercial or financial relationships that could be construed as a potential conflict of interest.

Copyright $\odot 2020$ Weber and Peuker. This is an open-access article distributed under the terms of the Creative Commons Attribution License (CC BY). The use, distribution or reproduction in other forums is permitted, provided the original author(s) and the copyright owner(s) are credited and that the original publication in this journal is cited, in accordance with accepted academic practice. No use, distribution or reproduction is permitted which does not comply with these terms. 